\title{
Uma Ferramenta de Simulação de Redes Multimídia Baseada no Modelo Fluido
}

\author{
P. H. P. de Carvalho, R. M. Lemos, T. F. Bento, G. A. Rosa e P. S. Barreto
}

\begin{abstract}
Resumo- Este trabalho apresenta os conceitos e a implementação de uma ferramenta para a simulação de redes multimídia com base no modelo fluido. $O$ simulador desenvolvido propõe a utilização da modelagem de fluxos fluidos contínuos em lugar da simulação individual dos pacotes de uma rede. O objetivo da modelagem de fluxos fluidos é produzir um número menor de eventos para diminuir custos computacionais para a simulação de redes complexas. Foram feitos experimentos para comparação o desempenho da ferramenta proposta com outros simuladores existentes e verificou-se que os resultados obtidos são coerentes, o que permite considerar a ferramenta como promissória na simulação de redes complexas.

Palavras chave- Simulador de redes (network simulator), Simulação de eventos discretos (discrete events simulation), Simulação Fluida (fluid simulation), Modelo de tráfego fluido (fluid traffic model).
\end{abstract}

\section{INTRODUÇÃO}

A redes de comunicação multimídia experimentaram um crescimento muito rápido nas últimas décadas. A complexidade envolvida na análise destas redes não permite que alguns pressupostos derivados dos modelos analíticos tradicionais sejam aplicados diretamente. Por exemplo, sabe-se hoje que o tráfego agregado nessas redes se aproxima mais de modelos fractais que dos Markovianos. Mesmo quando modelos analíticos podem ser utilizados, os simuladores são usados para validar as análises [1].

As simulações em nível de pacote têm sido amplamente utilizadas como ferramenta para avaliar diferentes características dos sistemas [1,2]. Apesar desta técnica de simulação ser uma das mais tradicionais para medir ou dimensionar o desempenho de uma rede, pode-se tornar muito custosa devido ao tamanho e a complexidade das redes a serem simuladas $[3,4]$.

Os simuladores com base em pacotes são ferramentas que, com graus aceitáveis de precisão, podem modelar uma rede e prover informações acerca do comportamento dos seus elementos. Mas na prática, este tipo de simulação está limitada pela capacidade computacional, seja pela quantidade de memória requerida ou pelo tempo gasto com processamento $[1,3,5]$.

Com o objetivo de desenvolver ferramentas mais eficientes para simulações de redes, outras técnicas têm sido

Lemom/Labcom -Departamento de Engenharia Elétrica e Departamento de Computação, Universidade de Brasília-DF, Campus Darcy Ribeiro, CEP 71000-000 paulo@ene.unb.br, rlemos@unb.br, tiago@labcom..unb.br, pris@cic.unb.br. estudadas nos últimos anos. As técnicas podem ser divididas em três categorias [6]: (a) modelos baseados no poder computacional, que aumentam a eficiência da simulação através do uso de processadores mais poderosos e recursos de multi-processamento; (b) modelos baseados em tecnologia de simulação que utilizam algoritmos mais eficientes; c) modelos de simulação, que se estruturam na idéia de aumentar o nível de abstração da simulação, para que o número de eventos envolvidos seja menor e se promova um ganho na eficiência.

Este trabalho consiste no desenvolvimento de um simulador que pertence à categoria de modelos de simulação, o modelo fluido.

O modelo fluido processa o tráfego como um fluxo fluido contínuo em vez de pacotes únicos. Um simulador fluido registra a mudança na taxa fluida na fonte e na fila enquanto que um simulador de pacotes registra os eventos de todos os pacotes no sistema [2,3,7]. Dessa forma, esperase que a quantidade de eventos necessários para representar o mesmo tráfego seja menor em uma simulação fluida.

Este artigo está organizado da seguinte forma: a seção II apresenta as principais características e conceitos teóricos necessários para a compreensão do modelo fluido. Na seção III é apresentada a ferramenta de simulação desenvolvida. A seção IV apresenta experimentos e comparações com outros simuladores de redes. Finalmente, a seção V apresenta as conclusões e expectativas para trabalhos futuros.

\section{O MODELO FLUIDO}

Em um sistema, em um dado instante de tempo, os modelos podem ser caracterizados como discretos, em que as variáveis de estado mudam instantaneamente em pontos separados no tempo e os contínuos, em que as variáveis mudam continuamente ao longo do tempo [8].

Conforme o avanço do tempo de simulação, o modelo pode ser classificado em orientado a eventos em que a simulação progride no instante de ocorrência do próximo evento, e os orientados ao tempo em que o tempo simulado avança em intervalos uniformes.

Um dos métodos mais utilizados para a caracterização de redes é a simulação de eventos discretos baseado em pacotes. Estes simuladores podem modelar um sistema com grande precisão, mas em contrapartida, o custo computacional, como o gasto com processamento ou memória pode se tornar muito alto, devido ao número de 
eventos gerados $[1,5,6,9]$. Uma alternativa para diminuir a quantidade de eventos tratados durante a simulação é o modelo fluido, no qual fontes de tráfego em nível de pacotes são substituídas por fontes fluidas.

\section{A. Simulação fluida}

A idéia principal do modelo fluido é abstrair o conceito de pacotes individuais. Com a modelagem baseada em pacotes, o simulador deve tratar os eventos de todos os pacotes individuais na rede e para a modelagem fluida, é necessário somente tratar os eventos de mudança de taxa nos pontos da rede.

A abstração do tráfego ocorre quando um fluxo de pacotes pouco espaçados é considerado do mesmo fluxo fluido com uma taxa fluida constante. Pequenas variações de tempo entre pacotes são abstraídas do modelo, desta forma diminui-se o número de eventos gerados.

Em um simulador convencional o número de eventos é proporcional ao número de pacotes produzidos pela fonte, enquanto no simulador fluido é proporcional ao número de transições da taxa [6].

\section{B. Modelo de fila fluida}

Uma diferença importante da fila por pacotes para a fluida é que mais de um fluido poderá compartilhar a taxa de serviço da fila ao mesmo tempo e fluidos de diferentes fontes podem chegar simultaneamente.

Como apresentado em [6], a taxa de chegada fluida total na fila com $N$ fontes fluidas, com política de agendamento FIFO e taxa de serviço $c$ é apresentada na Eq. 1, em que $a_{k}(t)$ é a taxa de chegada fluida da $k$-ésima fonte na fila.

$$
a(t)=\sum_{k=1}^{N} a_{k}(t)
$$

A dinâmica do tamanho da fila pode ser descrita pela relação recursiva da Eq.2 para $\tau_{i} \leq t \leq \tau_{i+1}$, em que $\tau$ é o instante em que a taxa fluida de chegada agregada muda.

$$
q(t)=\max \left(0, q\left(\tau_{i}\right)+(a(t)-c)\left(t-\tau_{i}\right)\right)
$$

Considere-se uma fila com buffer de tamanho $B$ que pode variar entre 0 e $\infty$. A quantidade de fluido armazenado no buffer em um instante $t$ será 0 ou o fluido armazenado no instante mais a quantidade de fluido que excede a taxa de serviço da fila desde o instante $\tau_{l}$ é dado por $a(t)-c$.

Para uma fila com buffer de capacidade finita, $B<\infty$, tem-se o caso em que poderá ocorrer perda de fluido quando o buffer da fila está saturado em certo instante de tempo e a taxa de chegada agregada é maior do que a taxa de serviço $a(t)>c$. A dinâmica do tamanho da fila para este caso mais restritivo é representada na Eq.3.

$$
q(t)=\min \left(B, q\left(\tau_{i}\right)+(a(t)-c)\left(t-\tau_{i}\right)\right)
$$

de chegada agregada for maior do que a taxa de serviço da fila, que será limitada pelo tamanho do buffer $B$.

\section{Efeito Ripple}

Uma mudança na taxa do fluxo que alimenta uma fila deve induzir uma mudança na taxa de partida fluida de todos os outros fluidos que compartilham a fila ao mesmo tempo. Isso deve produzir um incremento no número de eventos a serem executados na simulação, pois cada novo fluido formado será um novo evento.

Esse efeito ocorre devido à mudança na taxa de saída do próprio fluido ou à alteração na taxa dos outros fluidos que compartilham a fila.

A quantidade de mudanças dos processos de saída será maior do que dos processos de entrada e isso se propagará por toda aquela rota. Como o fluxo de saída da fila afeta todos os fluxos através da rota, a freqüência de mudança de taxa fluida continuará a aumentar. Este fenômeno é o efeito Ripple e pode tornar a simulação mais custosa do que a simulação por pacotes discretos.

A quantidade de eventos aumenta muito na medida em que os fluidos atravessam a fila, o número de mudanças de taxa na saída da fila será maior do que o número de mudanças de taxa na entrada da fila.

Esse efeito pode até tornar o simulador fluido mais custoso em relação à necessidade de processamento do que um simulador por pacotes. Os resultados apresentados em [6] mostram que uma rede com política de atendimento WFQ (Weighted Fair Queueing) apresenta menos este efeito quando implementadas as políticas FIFO (First In First Out).

\section{Modelo de fonte fluida}

Considere-se um fluxo de pacotes aleatoriamente espaçados. Para abstrair este tráfego em fluidos, deve se dimensionar um intervalo entre pacotes que determina a formação de um novo bloco.

Um fluido é um conjunto de pacotes agrupados, em que o que determina o início e fim entre fluidos é um intervalo entre blocos, que deve ser determinado antes da abstração do tráfego de pacotes.

Portanto o intervalo entre blocos será a menor diferença entre pacotes que estarão dentro do mesmo fluido. $\mathrm{O}$ próximo pacote que for gerado com um intervalo maior que o intervalo entre blocos será modelado como pertencente ao próximo fluido. Assim obtém-se um trafego fluido modelado a partir de um arquivo de tráfego de pacotes. $\mathrm{Na}$ Fig.1 exemplificá-se esse conceito.

A Fig.1 ilustra um tráfego de pacotes, com certa aleatoriedade entre os intervalos entre pacotes. Pode-se observar que para os três primeiros pacotes, o intervalo entre eles é menor que três, portanto pertencem ao mesmo fluido. 


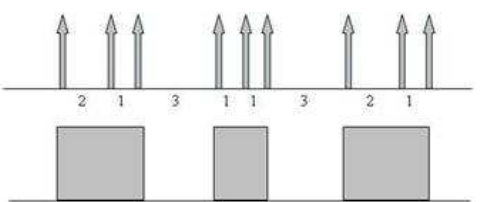

Fig. 1 Modelagem fluida

Quando o quarto pacote chega ou é gerado, o intervalo para o terceiro pacote é maior que o intervalo definido, portanto este pacote passará a pertencer a um novo fluido.

Um modelo de Markov com dois estados, on/off pode ser utilizado para a modelagem de uma fonte de pacotes, conforme mostrado na Fig.2. A taxa de transição do estado on para off e vice-versa é representada por $\lambda$ e $\mu$, respectivamente. $\mathrm{O}$ tempo de cada estado é exponencialmente distribuído. Quando a fonte estiver no estado ligado, pacotes são gerados com uma taxa $\gamma$.

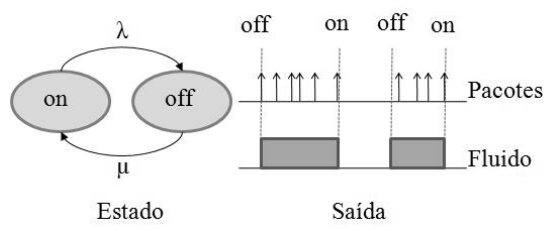

Fig. 2. Fonte de pacotes

O tamanho dos pacotes pode ser aleatório ou constante. Para fontes fluidas a idéia é bastante semelhante. Quando a fonte está no estado on, fluidos são gerados em forma de fluxo a uma taxa constante, e quando a fonte está no estado off, o fluxo é interrompido. Como na geração de pacotes, a geração de fluidos pode seguir alguma distribuição de probabilidade.

A taxa do fluido gerado na fonte é constante, mas pode mudar quando este fluido passar por um elemento de rede. Assim são formados desníveis na taxa do fluido, o que causa variações na sua intensidade.

\section{E. Moléculas fluidas}

Durante o processo de abstração do modelo, podem se perder informações sobre cada pacote individual. Para diminuir esse efeito, é utilizado o conceito de moléculas fluidas.

As moléculas fluidas são elementos emitidos pelas fontes que não têm volume, não afetam o nível nas filas e são usadas para medir a qualidade do serviço na simulação [7]. Esses objetos discretos são emitidos pela fonte e trafegam ao longo da rede.

Uma importante característica da molécula é que ela pode atuar em todos os elementos por onde passa. Sempre que uma molécula é recebida por um elemento de rede ela é manipulada e suas ações são determinadas pela sua programação.

\section{O SIMULADOR FLUIDO}

A ferramenta para simulação fluida implementada neste trabalho consiste em uma biblioteca modular de elementos de rede, um núcleo de simulação estruturado e um sistema para coleta de resultados.

A linguagem Java foi utilizada para o desenvolvimento. Dessa forma, o nível de base da ferramenta é a própria Máquina Virtual Java [10,12]. O segundo nível é o núcleo de simulação, que é o mecanismo de manipulação de eventos discretos, responsável pela execução da simulação, gerenciamento do avanço de tempo e execução dos processos dos componentes da rede. Foi construído a partir da Estrutura Escalonável de Simulação, ou SSF (Scalable Simulation Framework) [13]. O principal objetivo desta estrutura é dar suporte a simulações de alto desempenho $[2,14,15]$.

O conjunto objetos de redes de comunicação foi criado a partir de elementos básicos, com base em cinco categorias de elementos propostos em [7,16]. São eles: fonte de fluidos, coletor, filas, comutador e enlace.

\section{A. Fonte}

Uma fonte, também chamada de fonte on/off produz fluido a uma taxa constante somente no estado on. Os eventos são gerados nas transições entre estados. Os períodos dos estados on e off, assim como a intensidade do fluido a cada período ligado é determinado por um componente auxiliar chamado comportamento de fonte.

O comportamento de fonte pode ser implementada de acordo com características desejadas. Os períodos de tempo de cada estado podem ser constantes, possuir uma sequiência de valores predefinidos (como a leitura de um arquivo de tráfego) ou seguir alguma distribuição aleatória. Existem três implementações de comportamento de fonte: a) comportamento constante: os períodos consecutivos de on e off seguem um valor constante; b) comportamento exponencial: os intervalos de tempo dos períodos seguem uma distribuição aleatória exponencial; c) comportamento por arquivo de tráfego: este comportamento faz uma aproximação entre uma fonte de pacotes (representado por um arquivo de tráfego) para um modelo fluido.

O modelo do último item é uma proposta de abstrair a fonte fluida a partir de um arquivo com informações de tráfego.

As fontes de moléculas são objetos introduzidos nas fontes e têm finalidade de gerar moléculas naquele fluido. Uma fonte pode ter mais de uma fonte de moléculas, mas estas são produzidas e associadas ao mesmo fluido. A taxa de emissão de molécula é implementada conforme definido em [7].

\section{B. Coletores}

O coletor é o ponto final de um fluido ou molécula. A um coletor pode ser adicionado um ou mais objetos para obtenção de resultados.

Uma implementação é o coletor de atraso que é o ponto final das moléculas de atraso para computar os cálculos de atraso fim a fim de um ou mais fluidos. 


\section{Enlace}

Os enlaces são elementos que, ao receber um evento, o propagam pelo seu canal de saída com um atraso constante e maior ou igual a zero. Atualmente, apenas uma classe faz parte deste pacote e se trata de um enlace unidirecional. Portanto são necessários dois enlaces deste tipo para se fazer a comunicação nos dois sentidos.

\section{Fila}

A fila fluida é definida para valores com capacidade de transmissão $c>0$ e tamanho máximo de buffer $B \geq 0$. Em um determinado instante de tempo $t$, a fila possui três variáveis internas que caracterizam seu estado: a taxa total de chegada $a(t)$, a taxa total de saída $d(t)$ e o volume de buffer $q(t)$. Um evento na entrada recebido em um instante $t=\tau$ somente poderá ser refletido na saída após a fila $q(\tau)$ for consumida, ou seja, no instante $t_{\text {Fila }}$, conforme mostrado na Eq. 4. Sempre que um evento é recebido pela fila, o volume de buffer é calculado de acordo com essa equação.

$$
t_{\text {Fila }}=\tau+\frac{q(\tau)}{c}
$$

O volume total acumulado no buffer desde a última atualização e esse intervalo de tempo são passados para os elementos de prova adicionados àquela fila. Em [17] é descrita maneira de implementar o cálculo do volume total de buffer.

Sempre que ocorre alguma perda no buffer, os elementos de prova recebem três informações: o volume perdido, o instante de início da perda e o intervalo de duração. $\mathrm{O}$ volume fluido perdido em um período de perda é dado pela Eq.5.

$$
L=\int_{\tau_{n}}^{\tau_{n+1}}[a(t)-c] d t
$$

\section{E. Comutador}

O nó de comutação é um elemento que possui um canal de entrada e um ou mais canais de saída. Ao receber um evento de entrada, retransmite o evento em um dos canais de saída com atraso zero. A decisão de em qual canal de saída deve acontecer essa retransmissão é feita por um objeto chamado tabela de comutação.

\section{RESULTADOS EXPERIMENTAIS}

\section{A. Modelagem de tráfego fluido}

Nesta seção apresentá-se a modelagem de um tráfego de pacotes como um fluxo fluido. Um fluxo de pacotes aleatoriamente espaçados é abstraído e resulta em um tráfego fluido. $\mathrm{O}$ intervalo de abstração $\Delta t$ entre pacotes consecutivos deve ser escolhido de forma a melhor exprimir as características do tráfego. $\mathrm{O} \Delta t$ entre pacotes consecutivos é escolhido como a menor diferença entre pacotes que estarão dentro do mesmo fluido, o próximo pacote que for gerado com um intervalo maior que o $\Delta t$ especificado será modelado como pertencente ao próximo fluido.

Inicialmente foi gerado o arquivo de tráfego por pacotes. Cada pacote tem o tamanho de 200 Bytes. Foi utilizado um padrão de repetição de intervalos entre pacotes para facilitar a análise, com o intervalo entre o primeiro e segundo pacote de $100 \mathrm{~ms}$, do segundo para o terceiro de $200 \mathrm{~ms}$ e do terceiro para o quarto de $400 \mathrm{~ms}$ e de forma cíclica, esse padrão se repete a partir do quarto para o quinto e assim sucessivamente.

A rede a ser analisada foi construída de acordo com a Fig.3 formada por uma fila com política de atendimento FIFO, com um coletor e três fontes, onde foi injetado o tráfego fluido gerado a partir do tráfego por pacotes. A diferença entre as três fontes é um atraso de $50 \mathrm{~ms}$ na fonte dois (F2) e de 100 ms na fonte três (F3) em relação à fonte um $(\mathrm{F} 1)$.

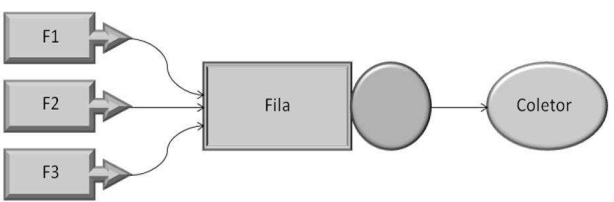

Fig. 3. Esquema da rede simulada

Para completar o processo, o arquivo de tráfego por pacotes de cada fonte foi abstraído do tráfego com três diferentes intervalos $\Delta t$, o primeiro intervalo de $100 \mathrm{~ms}$, o segundo de 200 ms e o terceiro de 300 ms. As Figs. 4 e 5 mostram a abstração de tráfego para 100ms e 200ms respectivamente. Nas figuras, os eixos horizontais representam o tempo na unidade $100 \mathrm{~ms}$, com o zero marcado pela intersecção com o eixo vertical à direita e o sentido crescente da direita para esquerda. $\mathrm{O}$ eixo vertical representa a taxa de transmissão, com uma unidade equivalente a 1 kbps. As barras superiores representam a taxa fluida referente ao fluido 1 , as intermediárias, ao fluido 2 e as inferiores ao fluido 3 .

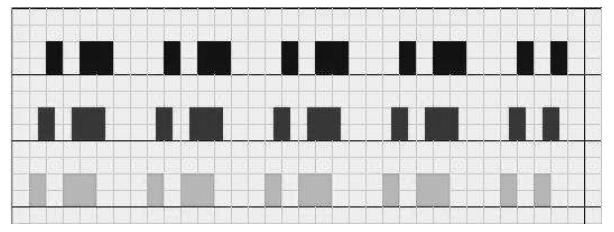

Fig. 4. Abstração para tráfego fluido com $\Delta \mathrm{t}=100 \mathrm{~ms}$

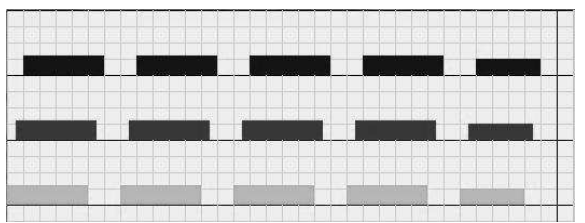

Fig. 5. Abstração para tráfego fluido com $\Delta \mathrm{t}=200 \mathrm{~ms}$

Cada tráfego passa por uma fila fluida FIFO com buffer infinito e taxa de transmissão de $2 \mathrm{kbps}$. $\mathrm{O}$ volume total que passa pela fila é de $18 k B$ e a medida de desempenho 
coletada foi a ocupação média do buffer.

Depois de iniciar a simulação foi coletada a saída da fila de cada fonte. Por restrições de espaço somente é mostrada a taxa de saída da fonte 2 na Fig. 6. O resultado da ocupação média do buffer resultante da simulação é apresentado na Tabela I.

Nos resultados da Tabela I observa-se que para um tipo de tráfego mais distribuído, a tendência é que a ocupação de buffer seja menor, no entanto ele é ocupado por mais tempo. Este resultado se mostra coerente, já que para uma taxa baixa de chegada, a fila atende a uma maior porção desse tráfego e uma parte menor precisa ficar armazenada no buffer.

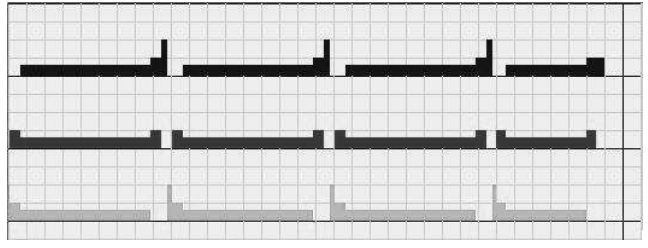

Fig. 6. Saída para o tráfego 2

TABELA I

OCUPAÇÃO MÉDIA DE BUFFER

\begin{tabular}{|l|l|l|l|}
\hline Fonte & $\begin{array}{l}\text { Ocupação } \\
\text { média (B/s) }\end{array}$ & Ocupação total (B) & $\begin{array}{l}\text { Duração } \\
\text { (s) }\end{array}$ \\
\hline Tráfego 1 & 2007,14 & 14050 & 7,0 \\
\hline Tráfego 2 & 1869,69 & 13648,75 & 7,3 \\
\hline Tráfego 3 & 1653,98 & 12404,86 & 7,5 \\
\hline
\end{tabular}

\section{B. Comparação com simulador de pacotes}

Considere-se um modelo simples de uma rede de pacotes formado por uma única fila com buffer infinito alimentada por uma fonte F1 de pacotes com transmissão a uma taxa constante (CBR - Constant Bit Rate) como mostra a Fig. 7.

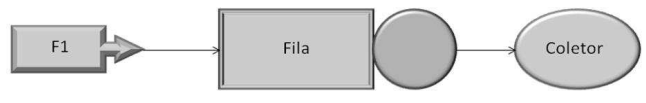

Fig.7 Esquema da rede simulada

A fila é FIFO com capacidade de transmissão de $1 \mathrm{kBps}$ e buffer infinito. A fonte gera um tráfego CBR com pacotes de tamanho 20 bytes, gerados durante 150 segundos. Para este caso foram feitas três simulações no NS-2 (Network Simulator 2), com diferentes taxas de transmissão de pacotes: $1050 \mathrm{kBps}, 2100 \mathrm{kBps}$ e $8400 \mathrm{kBps}$. Uma rede fluida semelhante foi montada, com uma fonte que produz um fluido único a uma taxa constante para cada um dos casos. Os resultados da comparação das medidas de atraso médio e o número de eventos gerados em cada tipo de rede são mostrados nas Tabelas II, III e IV.

Tabela II

REsUltados DA SIMULAÇ̃̃o À TAXA DE 1050 BPS

\begin{tabular}{|l|l|l|l|}
\hline Tipo Simulação & Tx & Eventos & Atraso Médio \\
\hline NS & $1050 \mathrm{Bps}$ & 23580 & 3,77 \\
\hline $\begin{array}{l}\text { Simulador } \\
\text { Fluido }\end{array}$ & $1050 \mathrm{Bps}$ & 9485 & 3.76 \\
\hline
\end{tabular}

TABELA III

RESULTADOS DA SIMULAÇÃO À TAXA DE 2100 BPS

\begin{tabular}{|l|l|l|l|}
\hline Tipo Simulação & Tx & Eventos & Atraso Médio \\
\hline NS & $2100 \mathrm{Bps}$ & 47147 & 82,36 \\
\hline $\begin{array}{l}\text { Simulador } \\
\text { Fluido }\end{array}$ & $2100 \mathrm{Bps}$ & 9485 & 82,57 \\
\hline
\end{tabular}

TABELA IV

RESULTADOS DA SIMULAC̃̃O À TAXA DE 8400 BPS

\begin{tabular}{|l|l|l|l|}
\hline $\begin{array}{l}\text { Tipo } \\
\text { Simulação }\end{array}$ & Tx & Eventos & Atraso Médio \\
\hline NS & $8400 \mathrm{Bps}$ & 188625 & 553,91 \\
\hline $\begin{array}{l}\text { Simulador } \\
\text { Fluido }\end{array}$ & $8400 \mathrm{Bps}$ & 9494 & 555,85 \\
\hline
\end{tabular}

A partir dos resultados das tabelas, pode-se afirmar que na medida em que a taxa de transmissão da fonte aumenta, também aumenta o atraso médio. Nos três casos os valores obtidos na simulação por pacotes e na simulação fluida foram compatíveis. Pode-se observar que foram gerados valores extremos para facilitar a análise de resultados.

Outra importante observação é em relação ao número de eventos gerados pela simulação. No simulador de pacotes, a quantidade de eventos gerados é diretamente proporcional ao número de pacotes inseridos na rede. $\mathrm{O}$ aumento na taxa de transmissão não afeta a quantidade de eventos gerados para a simulação fluida.

\section{Comparação com simulador fluido}

O objetivo desta seção é comparar o desempenho desta ferramenta com um simulador fluido já desenvolvido. Em [7] foi apresentado o FluidSim, uma ferramenta para simular modelos de rede de telecomunicação de alta velocidade. A escolha do FluidSim se deve a possibilidade de obter medidas de desempenho para comparação com a ferramenta proposta neste artigo.

A rede a ser simulada [7] foi montada conforme a Fig. 8 a fim de medir o atraso fim-a-fim e nível de buffer e comparar com os resultados obtidos no simulador fluido.

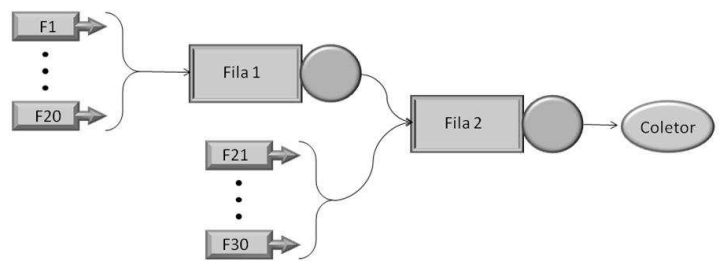

Fig. 8 Esquema da rede simulada

Os parâmetros definidos para esta simulação foram consideram as fontes $\mathrm{F} 1$ até F20 como on/off, exponencialmente distribuídas com um tempo médio de 10 ms entre períodos de on e off. Todas as fontes têm taxa média de $7 \mathrm{Mbits} / \mathrm{s}$ e taxa de pico de $15 \mathrm{Mbits} / \mathrm{s}$.

As fontes de F21 até F30 são on/off exponencialmente distribuídas com um tempo médio de $10 \mathrm{~ms}$ entre os períodos. Todas as fontes têm taxa média de $6 \mathrm{Mbits} / \mathrm{s}$ e taxa de pico de $15 \mathrm{Mbits} / \mathrm{s}$. As duas filas são idênticas com 
taxa de serviço 149,76 Mbits/s e tamanho de fila infinito.

Um fluxo agregado de dez fontes que passa pela Fila 1 também passa pela Fila 2, o fluxo das outras dez fontes passa somente pela Fila 1.

Similarmente a [7], a simulação foi executada trinta vezes. Os resultados para medidas de atraso apresentados na Tabela $\mathrm{V}$ e os resultados para nível médio de filas são apresentados na Tabela VI. Esses resultados comparativos permitem concluir que o simulador desenvolvido neste trabalho tem medidas de desempenho dentro do intervalo de confiança analisado para o FluidSim.

TABELA V

COMPARAÇÃO DE ATRASO MÉDIO ENTRE DOIS SIMULADORES FLUIDOS

\begin{tabular}{|l|l|l|}
\hline Fontes & $\begin{array}{l}\text { Atraso médio }(\mathbf{m s}) \\
\text { Simulador }\end{array}$ & $\begin{array}{l}\text { Atraso médio (ms) } \\
\text { FluidSim }\end{array}$ \\
\hline $1-20$ & 3,46 & 3,488 \\
\hline $21-30$ & 0,76 & 0,780 \\
\hline
\end{tabular}

TABELA VI

COMPARAÇÃO DE NÍVEL MÉDIO DE FILA ENTRE DOIS SIMULADORES FLUIDOS

\begin{tabular}{|l|l|l|}
\hline Fila & $\begin{array}{l}\text { Nível de fila (kbit) } \\
\text { Simulador }\end{array}$ & $\begin{array}{l}\text { Nível de fila (kbit) } \\
\text { FluidSim }\end{array}$ \\
\hline 1 & 390,07 & 393,9 \\
\hline 2 & 95,65 & 96,41 \\
\hline
\end{tabular}

\section{CONCLUSÕES E TRABALHOS FUTUROS}

Neste trabalho foram apresentados os conceitos teóricos e o desenvolvimento de uma ferramenta de simulação para redes com base na simulação fluida.

Foram detalhadas as características do modelo, como fontes e filas fluidas. Foram apresentados alguns problemas do modelo, como o efeito Ripple, que pode diminuir o desempenho da simulação, e a perda de consistência que ocorre na modelagem do tráfego fluido quando se abstrai muito os intervalos entre pacotes.

Foi proposto um modelo de abstração de pacotes onde estes são agrupados em fluidos de acordo com o intervalo definido para a abstração. As simulações demonstraram que, diferentes valores para esse intervalo podem fazer com que os resultados variem significativamente.

Em uma comparação entre a fila fluida do simulador com uma fila por pacotes do NS-2 verificou-se que para o tipo de tráfego analisado, os resultados de medidas obtidas foram equivalentes. Em ambos, a variação na taxa de chegada na fila produz a mesma mudança no atraso médio. No entanto, conforme a taxa aumenta o simulador por pacotes gera um número maior de eventos, enquanto este permanece constante para o simulador fluido. Isso mostra que a estimação de atraso através das moléculas de fluido produz um resultado razoável, porém gera um número menor de eventos.

Também foram feitas comparações com um simulador fluido semelhante. Duas medidas de desempenho de rede foram analisadas: atraso médio e ocupação de buffer. No conjunto de simulações realizadas, os resultados foram coerentes.

Como trabalho futuro, se propõe um estudo formal sobre a interferência dos parâmetros escolhidos para abstração de um tráfego fluido a partir de um tráfego de pacotes sobre os resultados das simulações, principalmente para tráfegos com características de multifractalidade.

\section{REFERÊNCIAS}

[1] Fujimoto, R.M.; Perumalla, K.; Park, A.; Wu, H.; Ammar, M.H.; Riley, G.F. Large-scale network simulation: how big? how fast?'”. In: 11th IEEE/ACM International Symposium on Modeling, Analysis and Simulation of Computer Telecommunications Systems, pp.: $116-123,2003$.

[2] Nicol, D. M., J. Liu, M. Liljenstam, and G. Yan. Simulation of large-scale networks using SSF. In Proceedings of the 2003 Winter Simulation Conference ed. S. Chick, P. J. Sánchez, D. Ferrin, and D. J. Morrice, 650-657. Piscataway, New Jersey: Institute of Electrical and Electronics Engineers, 2003.

[3] Nicol, D. M., J. Liu and M. Liljenstam. Advanced concepts in large-scale network simulation. In Proceedings of the 2005 Winter Simulation Conference ed. M. E. Kuhl, N. M. Steiger , F. B. Armstrong, and J. A. Joines, 153-166. Piscataway, New Jersey: Institute of Electrical and Electronics Engineers, 2005.

[4] Jones, K. G. and Das, S. R. Parallel execution of a sequential network simulator. In Proceedings of the 2000 Winter Simulation Conference ed. J. A. Joines, R. R. Barton, K. Kang, and P. A. Fishwick, 418-424, 2000

[5] Liu, B., Guo, Y., Kurose, J., Towsley,D. , And Gong, W. 1999. Fluid simulation of large scale networks: Issues and tradeoffs. In Proceedings of the International Conferece on Parallel and Distributed Processing Techniques and Applications (Las Vegas, NV), 1999.

[6] Figueiredo D.R., Liu B., Guo Y., Kurose J., Towsley D. On the efficiency of fluid simulation of networks. Technical Report CMPSCI TR 04-82, Department of Computer Science, University of Massachusetts, Amherst, 2004.

[7] J. Incera, R. A. Marie, D. Ros, G. Rubino. FluidSim: a tool to simulate fluid models of high-speed networks. In: Performance Evaluation 44 - An International Journal, Elsevier Science B.V, p. 25-49, 2001

[8] Fernandez, Elizabeth e Valadas, Rui. Demonstrador Animado das Técnicas de Programação de Simuladores de Eventos Discretos. Utilizando o MATLAB, Revista do DETUA. Vol. 2, N 3, 1998.

[9] Liu, B., D. Figueiredo, Y. Guo, J. Kurose, and D. Towsley. A study of networks simulation efficiency : Fluid simulation vs. packet-level simulation. In Proceedings of the 2001 INFOCOM Conference, 2001.

[10] Java Technology. http://java.sun.com, acessado em 04 de dezembro de 2007, às 22:00.

[11] Sierra, Kathy e Bates, Bert. Head First Java. Editora Alta Books Ltda, 2005.

[12] Deitel, H. M. e Deitel, P. J. Java ${ }^{\mathrm{TM}}$ How to Program, Deitel \& Associates, Inc, 6 ${ }^{\mathrm{a}}$. Edição, 2004.

[13] SSFNet. http://www.ssfnet.org/homePage.html, acessado em 05 de dezembro de 2007, às 16:00.

[14] Cowie, James H. Scalable Simulation Framework API Reference Manual. Documentation Draft, 1999.

[15] MIRAI-SF Simulator 4.0 User Manual, National Institute of Information and Communications Technology. Document Version 4.0.0, 2006.

[16] Liu, Benyuan e Figueiredo, Daniel. Queuing Network Library for SSF Simulator. Dept. Of Computer Science, University of Massachusetts, 2005.

[17] Ros, David e Raymond. M. Loss caracterization in high-speed networks through simulation of fluid models. In: Telecommunication Systems 16, Kluwer Academic Publishers, p. 1,2, 73-101, 2001. 